\title{
GARCH Approach for Testing the Conditional Relationship between Risk and Return in the Jordanian Stock Market
}

\author{
Imad Zeyad Ramadan ${ }^{1}$ \\ ${ }^{1}$ Department of Finance, Applied Science University, Amman, Jordan \\ Correspondence: Imad Zeyad Ramadan, Associate Prof., Department of Finance, Applied Science University, \\ P.O. Box 166, Amman, Jordan. E-mail: i_ramadan@asu.edu.jo
}

Received: April 28, 2014

Accepted: May 12, 2014

Online Published: June 25, 2014

doi:10.5539/ibr.v7n7p98

URL: http://dx.doi.org/10.5539/ibr.v7n7p98

\begin{abstract}
This study aims to test the relationship between risk and return in Amman Stock Exchange (ASE), in order to identify the market's ability to reward investors who are willing to take on additional risk. Using daily return for the Market Capitalization Weighted Price Index of the Jordanian stock market for the period from the first trading day on year 2000 to the last trading day of the year 2013. The full period has been separated into two periods: before the global financial crisis (BGFC) and during the global financial crisis (DGFC), to show if there is any impact of the financial crisis on the relationship between the risk and return. The GARCH model has been employed after testing for normality, heteroscedasticity and stationary, all of which have concluded the preference of using the GARCH model approach. Results have concluded that the conditional relationship between risk and return at the FULL period did not support the trade-off- theory, where there has been no statistically significant effect of risk, measured by volatility, on the market return during the FULL period, nor in the Before Global Financial Crisis (BGFC) period. This result of the study supports the results of studies which concluded that the ASE is not efficient at the semi-strong level of efficiency.
\end{abstract}

Keywords: GARCH, risk and return, Amman stock exchange

\section{Introduction}

The risk-returns relationship continue to be a point of contention among researchers, and the recent experimental studies, that tested this relationship, predicted two confusing results with regard to the relationship between risk and return in the stock market. First their results suggested a reversed association between conditional expected returns and the conditional volatility of returns. Second, the results documented a significant time variation regarding the risk-return association. These empirical results are important, since they goes' in the opposite way of the strong obviousness of a positive relation between volatility and expected returns.

Based on the above, two questions come up obviously, firstly, are these finding consistent with both general equilibrium models and time series properties of variable? Secondly, what features are needed to create these counterintuitive deeds of expected returns and volatility?

There are two reasons that could explain the letdown of the literature to accomplish a perfect conclusion on the risk-return association. Firstly, the difficulty of observing the conditional market variance, and the needs of certain restrictions to identify it from past returns, and secondly, Misspecification of equation could leads to difficulty in measuring a positive risk-return association.

Recent experimental studies testing the relationship between risk and return come to the answers about the contradictory results in the early literature. Scruggs (1998) added an additional risk factor implied by Merton (1973) model, and stated that ignoring this factor will lead to miss-specified model, while adding the long-term government bond returns as a second risk factor, will lead to a confirmation of the positive relationship between expected return and risk. Campbell and Hentschel (1992), Guo and Whitelaw (2006) and Kim, et al. (2004) concluded a direct association between risk and return in cases where the volatility feedbacks were included. Ghysels, et al. (2005) reports a direct trade-off between the risk and return, utilizing the Mixed Data Sampling Approach to estimate variance, and lately Lundblad (2007) confirmed this result. Pastor and Stambaugh (2001) concluded the existence of structural breaks in the risk return relationship. 


\section{Relevant Literature}

The CAPM seen as a fundamental form employed to validate the impact of systemic risk on capital market proceeds, CAPM was displayed by Treynor (1962) and Sharpe (1964), who added to Markowitz (1952); modified more by Lintner (1965), Mossin (1966), Black (1972); and unmitigated by Fama and MacBeth (1973). CAPM expresses the anticipated return risk association, and used in pricing risky assets. CAPM is a single-factor, three-step portfolio approach that takes just the stock market risk variable in to account, and does not consider extra risk variables. Most importantly, the CAPM is very general: it assumes no particular distribution of returns and is consistent with any distribution with finite first and second moments. The CAPM is not, as it often claimed is not an equilibrium model because the distribution of returns is not an equilibrium distribution. Stock market risk, a systematic risk, does not belong to a specific portfolio, and cannot be diversified.

The broad idea of the CAPM is that investors have to be rewarded in two ways: time value of money and risk. The time value of money rewards the investors for giving up cash money temporally, while the risk rewards the investors for taking on extra risk, and is computed by taking a risk measure that compares the incomes from the asset to the market over a period of time and to the market premium.

Since CAPM was lashed due to its impracticable assumptions (Tunali, 2010), the model has been developed to take into account other variables. Ross (1976) worked to prove that the market risk is not the only determinant of the systematic risk of the stock returns. Ross developed the CAPM by creating a multi-variable asset pricing form, Arbitrage Pricing Theory (APT), as a substitute to CAPM. The APT model is a linear relationship connecting external risk variables that have an influence on the asset's return, stock market risk and the asset's anticipated return.

Using Ross's (1976) APT model, Chen, Roll and Ross (1986), investigated a set of economic variables; oil prices, inflation, and market returns, as systematic risk factors. Roll and Ross investigated the association between economic variables and the US stock return, and concluded a powerful association among them. They concluded that stock returns are affected by systematic economic news.

Chen, Roll and Ross (1986) results have been used to examine the risk return relationship. Goriave (2004) examined the impact of the fundamental and macroeconomic risk factors on 47 of the Russian companies during the period 1999-2003 utilizing the APT model. Goriave has found that oil risk variable presents a considerable risk premium and that the exchange rate of the dollar seems more significant as a risk variable than the exchange rate.

Tunali (2010) investigated the macroeconomic factors stock return relationship in the Turkish stock market. Utilizing the Arbitrage Pricing Theory (APT) and using a vector auto-regression model, Tunali analyzed the expected relationship for the period 2002:01 and 2008:08. He concluded a significant association between macroeconomic variables and risk factors.

Using monthly based data, Izedonmi and Abdullahi (2011) tested the validity of the APT on the Nigerian Stock Exchange. Izedonmi and Abdullahi examined the impact of market capitalization, inflation and exchange rate on twenty sectors of the NSE by utilizing the ordinary least squares model (OLS). No significant impacts of the risk factors tested were found on the stocks' return for the NSE.

The CAPM and the APT models are very helpful tools, numerous applied researches used these two models to approximate the unconditional association between risk variables and stock return, however there are certain restrictions (Campbell \& MacKinlay, 1997; Basher \& Sadorsky, 2006). As the theory expects a trade-off between risk $(\beta)$ and ex ante expected returns $E(R)$, many applied Researches utilize the ex post realized returns $R(R)$ instead of ex ante $E(R)$. Pettengill et al. (1995) concluded that if the $R(R)$ is utilized as a replacement for the $E(R)$ to predict the CAPM, the association between the risk proxy $\beta$ and the return must be conditional on the relationship between the realized market return $\mathrm{R}(\mathrm{Rm})$ and the risk-free rate $\left(R_{f}\right)$. Pettengill et al. then present a conditional association between risk and the $\mathrm{R}(\mathrm{R})$ as a replacement approach to that used by Fama and MacBeth (1973). Fama and MacBeth decided whether the path of the market is "upward" or "downward" based on the relationship between the $\mathrm{R}\left(\mathrm{R}_{\mathrm{m}}\right)$ and $R_{f}$, and split the "up" market from the "down" market to generate a conditional association between risk variables and the $R(R)$.

The upward and downward markets can be represented by the following equation:

$$
M_{p}=R_{m}-R_{f}
$$

Where $M_{p}$ is the market premium; $R_{m}$ is the market return and $R_{f}$ is the risk free rate of return.

If the market premium is $>0$, the market is "upward"; if market premium is $<0$, the market is "downward". As 
the market premium is $>0$, the association between $\beta$ and the return will be direct relationship. However, if market premium is negative, the investor will keep the risk-free assets that have a low $\beta$, and the association between $\beta$ and return will be inverse relationship. So, as the association between $E(R)$ and risk is always a direct relation, the association between $\mathrm{R}(\mathrm{R})$ and risk can be both direct or inverse depending on market premium.

Pettengill et al. (1995) used this approach in order to identify the conditional return risk association in the US stock market. Pettengill et al. (1995) used the $\mathrm{R}(\mathrm{R})$ and divided the US stock market into upward and downward markets. The results have found that a direct connection is always predicted between $\beta$ and $E(R)$, but this relation is conditional on the market premium when $\mathrm{R} \otimes$ are employed. The results also have suggested that this relation is direct in an upward market and inverse in a downward market.

Following Pettengill et al. (1995) approach, Isakov (1999), for the Swiss stock market, examines the risk return relationship, and founds that the association between risk and return is significant and subject to the market trend. The results also concluded that $\beta$ is a significant determine of risk. Fletcher (2000) investigates the conditional risk return association in the stock markets of eighteen developed countries. Results indicate a significant positive return and risk association in upward market periods and a significant negative return and risk association in downward market periods. Tang and Shum (2003) and Theriou et al. (2010) confirmed Fletcher (2000) results.

Salman (2002) investigates the risk-return relationship in Istanbul Stock Exchange, utilizing the GARCH model. The results indicate a positive association between risk and return and fluctuations in trading size and return through the study period.

Ghysels et al. (2005) examined the return and risk association in US stock market using daily and monthly prices. The research engaged different methodologies such as ICAPM and GARCH and the results expose a positive connection between risk and return. Ghysels et al. (2005) also reveal new results regarding the asymmetric response of volatility to positive and negative return blows. Contrasted with negative blows, positive blows have a larger effect on mean returns; slower to be included into the conditional variance, and are much more constant and account for the constant nature of the conditional variance process.

Shin (2005) investigated the association between risk and return in 14 international emerging markets. Employing weekly base data and utilizing a GARCH model, Shin found a statistically significant direct risk return relationship in only three of the tested markets.

Khediri and Muhammad (2008) investigated the instability of the UAE stock market using GARCH and ARCH models during years 2001-2005. The outcomes showed that the models used are able to predict market volatility termed by means of low, medium and high volatility. In addition, based on the non linear threshold autoregressive methodology, Khediri and Muhammad recognized a significant leverage impact, such that a stock price lessen would have a larger effect on later volatility than a stock price raise with the same scale.

\section{Research Data and Methodology}

Daily closing prices index, Market Capitalization Weighted Price Index, for the Jordanian stock market, Amman Stock Exchange (ASE), were utilized for the period from the first trading day on year 2000 to the last trading day of the year 2013. The full period was separated into two periods: the first sub period goes on from Jan. 2, 2000 to Aug. 16, 2007 which represents the period before the global financial crisis $(B G F C)$, were the second one covers the period from Aug. 17, 2007 to Dec. 312013 and represents the period during the global financial crisis $\left(D G F C\right.$ ). Daily returns $\mathrm{R}_{\mathrm{t}}$ were calculated using the following equation:

$$
R_{t}=\frac{I_{t}}{I_{t-1}}-1
$$

Where $t$ is the day $t$ in the time-series; $R$ is the daily market return based on the market index; $I$ is the Market Capitalization Weighted Price Index.

The time period of the study, and the method of calculating the market returns resulted in a total of 3438 observations for the complete time period, in which it was separated to 1882 observations for BGFC period and 1555 observations for AGFC period.

In order to achieve the objectives of the study, and test its hypotheses, the study tested the computed returns time-series for normality, heteroscedasticity and stationary. So, the Jarque-Bera, Ljung-Box, Dickey-Fuller and ARCH-LM (6Lags) tests were employed.

Least square is a basic idea in statistics, and is broadly used in finance. Least squares determine how a dependent variable changes in respose to the variation of the independent variable. The difference between the actual and 
the predicted value is well-known as the residual. When building financial models, minimizing the sum of the squares of the residuals is considered. The least squares method presumes that the squared error has equal amount through the full data. This assumption is known as homoscedasticity. Financial data, time-series, has periods of low and high volatility, with periods of high volatility often clustering together. This is known as heteroscedasticity. In modeling, it means the residuals differ in amount. Volatility clustering means the data is auto correlated.

As the error term $\mathrm{u}$ at time $\mathrm{t}$ can be correlated with the error term at time $\mathrm{t}-1$ in a first-order autoregressive $(\mathrm{AR}(1))$ plot or with a range of lagged error terms in a general $\operatorname{AR}(\mathrm{p})$ plot, there can be autocorrelation in the variance $\sigma^{2}$ at time $t$ with its values lagged one or more periods. Such an autocorrelation has been experiented by researchers engaged in forecasting financial time series, such as stock prices. Such autocorrelation is known as; the Autoregressive Conditional Heteroscedasticity (ARCH) if the error variance is related to the squared error term in the previous term and Generalized Autoregressive Conditional Heteroscedasticity (GARH) if the error variance is related to squared error in several periods in the past.

In finance, the return of a stock may be influenced by its volatility (risk). The simplest way to estimate stock volatility is by computing the day's $t$ variance. The $\operatorname{GARCH}(p, q)$ model has two characteristic parameters; $p$ is the number of GARCH terms and $\mathrm{q}$ is the number of $\mathrm{ARCH}$ terms and adds a heteroscedasticity term into the mean equation. GARCH (p, q) has the following form:

$$
\begin{gathered}
R_{t}=\mu+b R_{t-1}+\lambda \sigma_{t}^{2}+\varepsilon_{t} \\
\varepsilon_{t} / \Omega_{t-1} \sim N\left(0, \sigma_{t}^{2}\right) \\
\sigma_{t}^{2}=\omega+\alpha_{1} \varepsilon_{t-1}^{2}+\beta_{1} \sigma_{t-1}^{2}
\end{gathered}
$$

Where $R_{t}$ the market return at day $t$ of the time-series, $\mu$ the conditional mean of the GARCH (p,q), $\varepsilon_{t}$ the residual which is limited to $\Omega_{\mathrm{t}-1}$ being normally distributed, $\lambda$ is the parameter of the relationship between the $R_{t}$ and the conditional variance (risk). Equation 3 indicates that today's market return is a function of yesterday's return, the conditional variance (risk) and today's residual. Equation 5 tells us that the conditional variance, $\sigma_{t}^{2}$, is a function of the yesterday's residual and yesterday's conditional variance. $\alpha_{1}, \beta_{1}$ in equation 5 are the parameters to be estimated, which point out the tendency of volatility shocks to continue over time, and the sum of $\alpha_{1}$ and $\beta_{1}$ indicate the degree of persistence in the conditional variance. Specifically, if the total of the two parameters are less than 1 , this will indicate a stationary variance in the time-series.

\section{Data Analysis}

Table 1 reveals the descriptive analysis of the market daily returns of the ASE Index for the full period of the study in addition to the BGFC period and AGFC period. The mean return of the ASE index and standard deviation for the full period are 0.003 and 0.157 respectively. An important note can be seen from Table 1 that the mean return and the standard deviation of the ASE index are greater in the BGFC period than in DGFC period which confirms the negative impact of the global financial crisis on the Jordanian stock market.

Table 1. Descriptive analysis

\begin{tabular}{lccccccccc}
\hline & N & AVER & $\begin{array}{c}\text { STD } \\
\text { DEV }\end{array}$ & SKEW & KURT & $\begin{array}{c}\text { Jarque-Bera } \\
\text { (JB) }\end{array}$ & $\begin{array}{c}\text { Ljung-Box } \\
\text { LB(1Lag) }\end{array}$ & $\begin{array}{c}\text { Unit } \\
\text { Root }\end{array}$ & $\begin{array}{c}\text { ARCH } \\
\text { LM } \\
(\mathbf{6 L a g s})\end{array}$ \\
\hline Full & \multirow{2}{*}{3438} & .0025 & .157369 & $58.21^{*}$ & $3405.05^{*}$ & $1.7 \mathrm{E}+09^{*}$ & $7.18^{*}$ & $-58.5^{*}$ & 0.10 \\
C.V. & & & & -- & -- & 5.99 & 3.84 & -1.1 & $(15.51)$ \\
p-value & & & & $0.00 \%$ & $0.00 \%$ & $0.00 \%$ & $0.91 \%$ & $0.00 \%$ & $98.8 \%$ \\
BGFC & 1882 & .0056 & .212456 & $43.21^{*}$ & $1872.13^{*}$ & $2.7 \mathrm{E}+08^{*}$ & 0.002 & $-43.3^{*}$ & 0.05 \\
C.V. & & & & -- & -- & 5.99 & 3.84 & -1.2 & $(15.51)$ \\
p-value & & & & $0.00 \%$ & $0.00 \%$ & $0.00 \%$ & $98.8 \%$ & $0.00 \%$ & $99.4 \%$ \\
DGFC & 1555 & -.0001 & .010923 & $-0.0127^{* *}$ & $4.982^{*}$ & $1.6 \mathrm{E}+03^{*}$ & $55.25^{*}$ & $-10.5^{*}$ & $68.36^{*}$ \\
C.V. & & & & -- & -- & 5.99 & 3.84 & -1.2 & $(15.51)$ \\
p-value & & & & $2.06 \%$ & $0.00 \%$ & $0.00 \%$ & $0.00 \%$ & $0.00 \%$ & $0.00 \%$ \\
\hline
\end{tabular}

$*$, **; significant at the $0.01,0.05$ respectively,

C.V. Critical Value. 
The Jarque-Bara (JB) test is a goodness-of-fit measure that measures the deviation from normality depending on the results of the kurtosis and skewness. JB can be formed as:

$$
J B=n\left[\frac{S^{2}}{6}+\frac{(K-3)^{2}}{24}\right]
$$

Where: JB is the Jarque-Bara test, $n$ the number of valid value in the sample size, $\mathrm{S}$ is skewness statistic value, $\mathrm{K}$ is the kurtosis statistic value.

The JB test is a test of the joint hypothesis that skewness and kurtosis are 0 and 3 in order, and the value of the JB test is expected to be 0 and the null hypothesis the JB test seeks to test whrther the data is from a normal distribution. This null hypothesis can be formed as:

$$
H_{0}: x \sim N(.)
$$

Where: $H_{0}$ is the null hypothesis, $x$ is the univariate time series data, $N($.$) the normal probability distribution.$

The $H_{0}$ will be rejected at level $\alpha$ if

$$
J B \geq x_{1-\alpha, 2}^{2}
$$

Where: $X_{1-\alpha, 2}^{2}$ is the chi-square probability distribution function with 2 degrees of freedom.

Table 1 shows that the JB value for the three tested periods are significantly high, indicating that the hypothesis of normality can be rejected at the 0.01 or less level using the JB test.

The Ljung-Box test (LB) is a type of statistical test for randomness, that test the overall randomness based on a number of lags instead of testing randomness at each distinct lag.

The LB test can be formed as:

$$
L B=n(n+2) \sum_{k=1}^{h} \frac{\hat{p}_{k}^{2}}{n-k}
$$

Where, $n$ the number of valid value in the sample size, $\hat{p}_{k}$ is the sample autocorrelation at lag $k$, and $h$ is the number of lags being tested.

The LB statistic has an asymptotic chi-square distribution with $h$ degrees of freedom and can be used to test the null hypothesis that the time series is not serially correlated, the null hypothesis for the LB test can be formed as:

$$
H_{0}=p_{1}=p_{2}=p_{3}=\cdots=p_{h}=0
$$

Where: $H_{0}$ is the null hypothesis, $p$ is the sample autocorrelation, $h$ is the number of lags being tested.

As for rejecting the null hypothesis, the test will reject the randomness hypothesis if:

$$
L B \geq X_{1-\alpha, h}^{2}
$$

Where, $L B$ is the computed value of the $L B$ test, $x_{1-\alpha, h}^{2}$ is the chi-square probability distribution function with $h$ degrees of freedom for the chi-square distribution.

The $L B$ test was used to test the time-series autocorrelations in the ASE Index daily returns at the 1 lag period. The results in table 1 obviously confirm the rejection of randomness at the 0.01 level of significance or less for the full and DGFC periods.

The Dickey-Fuller (DF) test has been used to investigate whether the ASE series' of returns has a unit root or not. The DF test is based on the without constant or trend regression equation as follows:

$$
\Delta y_{t}=\lambda y_{t-1}+u_{t}
$$

Where: $y_{t}$ is the series of returns at time $\mathrm{t}, \lambda$ is the nuisance parameter, $\mathcal{U}$ is the random error.

The null hypothesis to be tested is that the series returns of ASE have a unit root (non-stationary) which can be formed as:

$$
H_{0}: \lambda=0
$$

The null hypothesis is to be rejected if:

$$
D F_{t r}<t_{t r, \alpha}
$$

Where: $D F_{t r}$ is the computed value of the Dickey-Fuller unit root test, $t_{t r, \alpha}$ is the unit root t-test critical value at $\alpha$ significant level.

The results in table 1 show that the values of the DF unit root test for all tested periods $(-58.5,-43.3,-10.5)$ are 
smaller than the critical value of the unit root t-test at $1 \%$ significant level $(-1.1,-1.2,-1.2)$ respectively, therefore we reject the $H_{0}$, and conclude that the ASE returns have no unit root, and thus are stationary series at $1 \%$ or less significant level.

As for ARCH-LM (6 Lags) test, Table 1 shows that the ARCH value for; Full and BGFC periods are less than the critical values at 0.05 significant level indicating the insignificant appearance of the ARCH effect in ASE index returns for the two mentioned periods. As for DGFC period, Table 1 shows a high degree of volatility in ASE index returns, indicating the significant appearance of the ARCH effect in DGFC period.

In summary, the results of the descriptive statistical analysis above, show that the series returns of ASE is stationary series and neither random nor normally distributed, which confirms the advantage of using the GARCH model.

\section{Empirical Results}

Table 2 presents the coefficients of GARCH-M $(1,1)$ model $\left(\alpha_{1}, \beta_{1}\right)$ for the Full, BGFC and DGFC periods. The results show the significant form of the effect of GARCH in DGFC period. This provides an evidence of high volatility in the ASE index's return at 0.01 level during the global financial crises, as for the other two tested periods, the effect was insignificant. By looking at $\alpha_{1}$ and $\beta_{1}$ values, it is obvious that the value of $\alpha_{1}$ is less than $\beta_{1}$ for all periods, indicating that the effect of the past information on the return is less than that of the recent information.

Table 2. GARCH model $(1,1)$ coefficients

\begin{tabular}{lcccccc}
\hline & $\omega$ & $\alpha_{1}$ & $\beta_{1}$ & $\alpha_{1}+\beta_{1}$ & $\mu$ & $\lambda$ \\
\hline \multirow{2}{*}{ Full period } & 0.0248 & $0.003^{*}$ & 0.371 & \multirow{2}{*}{0.374} & 0.0074 & 0.0341 \\
& & $(4.641)$ & $(0.971)$ & & & $(0.871)$ \\
BGFC period & 0.031 & 0.227 & \multirow{2}{*}{0.258} & 0.00559 & 0.0254 \\
& \multirow{2}{*}{0.04519} & $(0.817)$ & $(0.091)$ & & & $(0.358)$ \\
DGFC period & 0.0291 & $0.018^{*}$ & $0.758^{*}$ & \multirow{2}{*}{0.867} & 0.0017 & $0.173^{*}$ \\
& & $(7.213)$ & $(11.912)$ & & & $(8.746)$ \\
\hline
\end{tabular}

*, Significant level at $1 \%$,

$\mathrm{Z}$ value is between parentheses.

The sign of the indicator $\lambda$ defines the relationship between volatility and return, as it is clear from the results in Table $2, \lambda$ is positive for all three tested periods, suggesting a positive association between the volatility (risk) and return, taking into account that the results were not statistically significant in Full and BGFC periods.

By scanning the results of the GARCH model for BGFC and DGFC periods, significant differences in the results between the two periods can be seen, While the result shows that the effect of the historical information $\left(\alpha_{1}\right)$ on the ASE index's return was less and statistically significant in the DGFC period, it shows that the current information $\left(\beta_{1}\right)$ effect on the return is higher and statistically significant in the DGFC period. Another finding from Table 2 is that the positive relationship between the volatility, as a proxy of the risk, and ASE index return's was statistically significant in the DGFC, and insignificant in BGFC. Finally, the stability of volatility in the market, which defined as $\alpha_{1}+\beta_{1}$, increased during the DGFC period as compared to the BGFC period.

\section{Conclusions}

The results of GARCH-M $(1,1)$ showed that the impact of historical information on the return of ASE index is significantly very low (close to zero) during the study period (FULL period). This result is consistent with the efficient market theory, and supports the results of studies which concluded that the ASE may be efficient at the weak level of efficiency.

Another result of the study is that the impact of the current information on the market was greater than the impact of historical information during the FULL period, this result supports the idea that investors value recent information more than they value past information, and it is consistent with the efficient market theory which states that the present information must affect the market, while the historical information should not affect the market. This result of the study supports the results of studies which concluded that the ASE is not efficient at the semi-strong level of efficiency. 
With regard to the conditional relationship between risk and return at the FULL period, the results of this study did not support the trade-off- theory, which suggests a statistically significant positive relationship between the risk borne by the investor from investing and the expected return of this investment, Although the results of this study during the DGFC period supported this theory.

\section{Acknowledgements}

The author is grateful to the Applied Science Private University, Amman, Jordan, for the financial support granted to this research project (Grant No. DRGS-2013-2014-31).

\section{References}

Basher, S. A., \& Sadorsky, P. (2006). Oil price risk and emerging stock markets. Global Finance Journal, 17, 224-251. http://dx.doi.org/10.1016/j.gfj.2006.04.001

Black, F. (1972). Capital market equilibrium with restricted borrowing. Journal of Business, 45, 445-455. http://dx.doi.org/10.1086/295472

Campbell, J. Y., \& Hentschel, L. (1992). No News is Good News: An Asymmetric Model of Changing Volatility in Stock Returns. Journal of Financial Economics, 31, 281-318. http://dx.doi.org/10.1016/0304-405X(92)90037-X

Campbell, J. Y., Lo, A., \& MacKinlay, A. C. (1997). The econometrics of financial markets. Princeton NJ Princeton University Press.

Chen, N. F., Roll, R., \& Ross, S. A. (1986). Economic forces and the stock market. Journal of Business, 59(3), 383-403. http://dx.doi.org/10.1086/296344

Fama, E., \& MacBeth, J. D. (1973). Risk, return and equilibrium: Empirical tests. Journal of Political Economy, 71, 607-636. http://dx.doi.org/10.1086/260061

Fletcher, J. (2000). On the conditional relationship between beta and return in international stock returns. International Review of Financial Analysis, 9, 235-245. http://dx.doi.org/10.1016/S1057-5219(00)00030-2

Ghysels, E., Santa-Clara, P., \& Valkanov, R. (2005). There is a Risk-Return Tradeoff After All. Journal of Financial Economics, 76, 509-548. http://dx.doi.org/10.1016/j.jfineco.2004.03.008

Guo, H., \& Whitelaw, R. F. (2006). 'Uncovering the Risk-Return Relation in the Stock Market. Journal of Finance, 61(3), 1433-1463. http://dx.doi.org/10.1111/j.1540-6261.2006.00877.x

Isakov, D. (1999). Is beta still alive? Conclusive evidence from the Swiss stock market. The European Journal of Finance, 5, 202-212. http://dx.doi.org/10.1080/135184799337046

Izedonmi, P. F., \& Abdullahi, I. B. (2011). The effects of macroeconomic factors on the Nigerian stock returns: A sectoral approach. Global Journal of Management and Business Research, 11(7).

Khedhiri S., \& Muhammad, N. (2008). Empirical analysis of the UAE stock market volatility. International Research Journal of Finance and Economics, 15, 249-260.

Kim, C. J., Morley, J. C., \& Nelson, C. R. (2004). Is there a Positive Relationship Between Stock Market Volatility and the Equity Premium? Journal of Money Credit and Banking, 36(3), 339-360. http://dx.doi.org/10.1353/mcb.2004.0055

Lintner, J. (1965). The valuation of risky assets and the selection of risky investments in stock portfolios and capital budget. Review of Economics and Statistics, 47, 13-37. http://dx.doi.org/10.2307/1924119

Lundblad, C. (2007). The Risk Return Tradeoff in the Long-Run: 1836-2003. Journal of Financial Economics, 85, 123-150. http://dx.doi.org/10.1016/j.jfineco.2006.06.003

Markowitz, H. (1952). Portfolio Selection. The Journal of Finance, 7(1), 77-91. Retrieved from http//www.jstor.org.proxy.lib.chalmers.se/stable/10.2307/2975974?origin=api

Merton, R. C. (1973). An Intertemporal Asset Pricing Model. Econometrica, 41, 867-888. http://dx.doi.org/10.2307/1913811

Mossin, Jan. (1966). Equilibrium in a Capital Asset Market. Econometrica, 35, 768-83. http://dx.doi.org/10.2307/1910098

Pastor, L., \& Stambaugh, R. F. (2001). The Equity Premium and Structural Breaks. Journal of Finance, 4, 1207-1231. http://dx.doi.org/10.1111/0022-1082.00365

Pettengill, G., Sundaram, S., \& Mathur, I. (1995). The conditional relation between beta and return. Journal of 
Financial and Quantitative Analysis, 30, 101-116. http://dx.doi.org/10.2307/2331255

Ross, S. (1976). The arbitrage theory of capital asset pricing. Journal of Economic Theory, 13, 341-360. http://dx.doi.org/10.1016/0022-0531(76)90046-6

Salman, F. (2002). Risk-Return-Volume relationship in an Emerging Stock Market. Applied Economics Letter, 9(8), 549-562. http://dx.doi.org/10.1080/13504850110105727

Scruggs, J. T. (1998). Resolving the Puzzling Intertemporal Relation between the Market Risk Premium and Conditional Market Variance: A Two-Factor Approach. Journal of Finance, 53, 575-603. http://dx.doi.org/10.1111/0022-1082.235793

Sharpe, W. (1964). Capital asset prices: A theory of market equilibrium under conditions of risk. Journal of Finance, 19, 425-442.

Shin J. (2005). Stock return and volatility in emerging stock markets. International Journal of Business and Economics, 4, 31-43.

Tang, G. Y. N., \& Shum, W. C. (2003). The conditional relationship between beta and returns: Recent evidence from international stock markets. International Business Review, 12, 109-126. http://dx.doi.org/10.1016/S0969-5931(02)00090-2

Theriou, N. G., Aggelidis, V. P., Maditinos, D. I., \& Sevic, Z. (2010). Testing the relation between beta and returns in the Athens Stock Exchange. Managerial Finance, 36(12), 1043-1056. http://dx.doi.org/10.1108/03074351011088441

Treynor, J. L. (1962). Toward a Theory of Market Value of Risky Assets. Unpublished manuscript. Final version in Robert A. Korajczyk (Ed.), Asset Pricing and Portfolio Performance (pp. 15-22). London: Risk Books,

Tunali, H. (2010). The Analysis of Relationships between Macroeconomic Factors and Stock Returns: Evidence from Turkey Using VAR Model. International Research Journal of Finance and Economics, 57.

\section{Copyrights}

Copyright for this article is retained by the author(s), with first publication rights granted to the journal.

This is an open-access article distributed under the terms and conditions of the Creative Commons Attribution license (http://creativecommons.org/licenses/by/3.0/). 